\title{
Biología y guerra: una perspectiva pragmática*
}

\author{
Biology and war: a pragmatic perspective
}

\author{
Anna Estany \\ Departamento de Filosofía, Univesidad Autónoma Barcelona, España \\ anna.estany@uab.cat
}

\begin{abstract}
Resumen
Una aproximación a la filosofía de la biología en el siglo XXI requiere ir más allá de su vertiente epistemológica, apostando por los aspectos pragmáticos, en el sentido del impacto social de la instrumentalización de los desarrollos biológicos. Dichos avances tienen tanto consecuencias beneficiosas como perjudiciales para la humanidad. Entre las últimas, está su utilización para conflictos bélicos, como resultado de los avances en biotecnología. El objetivo de este trabajo es abordar el papel de los conocimientos biológicos en las guerras, analizando algunos casos especialmente relevantes como el bioterrorismo, pero también otro tipo de conflictos en los que la biología, entendida en sentido amplio con sus distintas ramas, juega un papel importante. En primer lugar, introduciré los conceptos más importantes en la relación entre biología y guerra, teniendo en cuenta los precedentes históricos en esta materia. En segundo lugar, a partir de que la biología entra con fuerza en los conflictos bélicos, abordaré el caso del bioterrorismo como uno de los problemas más acuciantes en tanto en cuanto es una de las formas que toma la guerra en la actualidad, así como una de sus derivadas, el "agroterrorismo", que consiste en provocar la destrucción de cosechas o la muerte de ganado que alimenta a la población. En este sentido, examinaré otras formas de dirimir los conflictos en los que factores biológicos juegan un papel importante a la hora de establecer el dominio entre dos o más naciones o poblaciones enfrentadas, prestando
\end{abstract}

\footnotetext{
*Este trabajo ha sido financiado por el Ministerio de Ciencia, Innovación y Universidades dentro del Subprograma Estatal de Generación del Conocimiento a través del proyecto de investigación FFI2017-85711-P Innovación epistémica: el caso de las ciencias biomédicas.

Este trabajo forma parte de la red de investigación consolidada Grupo de Estudios Humanísticos de Ciencia I Tecnología (GEHUCT), reconocida y financiada por la Generalitat de Catalunya, referencia 2017 SGR 568.
}

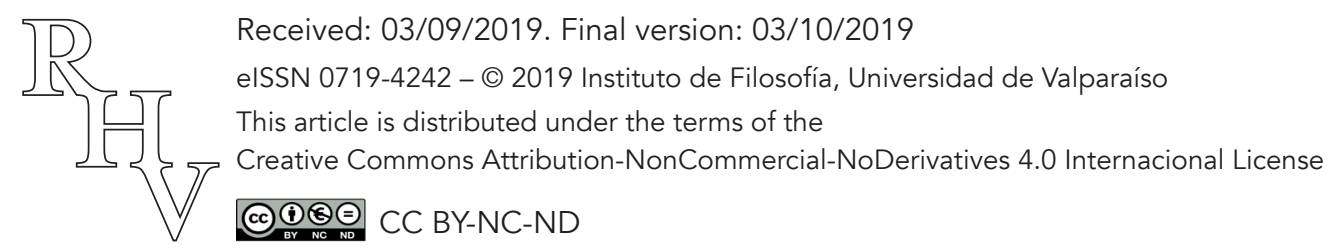


Biología y guerra: una perspectiva pragmática

Anna Estany

especial atención a la agricultura y a la ganadería. Respecto a los posibles modelos teóricos para analizar estos conflictos me centraré en la relación entre ciencia pura, aplicada y tecnología, los modelos metodológicos de las ciencias de diseño y la reflexión ética y moral.

Palabras clave: guerra biológica, bioterrorismo, agroterrorismo, ciencias de diseño, dilemas éticos.

\begin{abstract}
An approach to the philosophy of biology in the 21 st century requires going beyond its epistemological side, betting on pragmatic aspects, in the sense of the social impact of the instrumentalization of biological developments. These advances have both beneficial and harmful consequences for humanity. Among the latter, it is its use for military conflicts, as a result of advances in biotechnology. The objective of this work is to address the role of biological knowledge in wars, analyzing some especially relevant cases such as bioterrorism, but also other types of conflicts in which biology, broadly understood with its different branches, plays an important role. First, I will introduce the most important concepts in the relationship between biology and war, taking into account historical precedents in this area. Secondly, since biology enters in military conflicts, I will address the case of bioterrorism as one of the most pressing problems in that it is one of the forms that war is currently taking, as well as one of its derivatives, "agroterrorism", which consists in causing the destruction of crops or the death of livestock that feeds the population. In this regard, I will examine other ways of resolving conflicts in which biological factors play an important role in establishing dominance between two or more nations or populations facing each other, paying special attention to agriculture and livestock. Regarding the possible theoretical models to analyze these conflicts, I will focus on the relationship between pure, applied science and technology, the methodological models of design sciences and ethical and moral reflection.
\end{abstract}

Keywords: biological warfare, bioterrorism, agroterrorism, design sciences, ethical dilemmas.

\title{
1. Introducción
}

Una aproximación a la filosofía de la biología en el siglo XXI requiere ir más allá de su vertiente epistemológica, apostando por los aspectos pragmáticos, en el sentido del impacto social de la instrumentalización de los desarrollos biológicos, desde los insecticidas a los productos para engordar el ganado, entre otros muchos. Dichos avances tienen tanto consecuencias beneficiosas como perjudiciales para la humanidad. Entre las últimas, está su utilización para conflictos bélicos, que ha aumentado considerablemente en las últimas décadas como resultado de los avances en biotecnología. Sin embargo, la implicación en conflictos bélicos tiene más historia la física (bomba atómica) y la química (utilización de productos químicos tóxicos), siendo estudiadas y discutidas con más asiduidad que la 
intervención de la biología. En consecuencia, las discusiones sobre ciencia y tecnología suelen centrarse en estas disciplinas. Y lo mismo ocurre en los estudios sobre geopolítica y geoestrategia, como muestra el libro de Pedro Baños (2017) Así se domina el mundo. Desvelando las claves del poder mundial. Sin embargo, la biología ha entrado también a formar parte de los conflictos bélicos y militares y, en consecuencia, de los debates y contradicciones entre los propios científicos.

El objetivo de este trabajo es abordar el papel de los conocimientos biológicos en las guerras, analizando algunos casos especialmente relevantes como el bioterrorismo, pero también otro tipo de conflictos en los que la biología, entendida en sentido amplio con sus distintas ramas, juega un papel importante. En primer lugar, introduciré los conceptos más importantes en la relación entre biología y guerra, teniendo en cuenta los precedentes históricos en esta materia. En segundo lugar, a partir de que la biología entra con fuerza en los conflictos bélicos, abordaré el caso del bioterrorismo como uno de los problemas más acuciantes en tanto en cuanto es una de las formas que toma la guerra en la actualidad, así como una de sus derivadas, el "agroterrorismo", que consiste en provocar la destrucción de cosechas o la muerte de ganado que alimenta a la población. En este sentido, examinaré otras formas de dirimir los conflictos en los que factores biológicos juegan un papel importante a la hora de establecer el dominio entre dos o más naciones o poblaciones enfrentadas, prestando especial atención a la agricultura y a la ganadería.

Respecto a los posibles modelos teóricos para analizar este tipo de conflictos me centraré en la relación entre ciencia pura, aplicada y tecnología, en los modelos metodológicos de las ciencias de diseño y en la reflexión ética y moral. En el caso de la ética, hay que decir que el campo de la bioética ha sido muy desarrollado actualmente, aunque - fundamentalmente - se ha limitado a las cuestiones de salud a través de los comités de bioética en los hospitales. Aunque también tiene un papel importante en los centros de investigación en los que se utilizan animales a fin de que se cumpla la normativa que atiende a su bienestar. La propuesta que presento frente a la cuestión de biología y guerra es la necesidad de introducir la reflexión moral y ética en el análisis de los conflictos internacionales, para lo cual es imprescindible que los comités que vayan a intervenir en dichos conflictos sean inter-trans-multidisciplinares a fin de abordar el conflicto desde los diversos elementos que intervienen en la guerra biológica, especialmente acuciante en el caso del bioterrorismo, pero no menos importante para las situaciones de hambruna provocadas por la destrucción de la producción agrícola y ganadera.

\section{Ciencia y guerra: una perspectiva histórica}

Seguramente para ser más precisos habría que hablar de "conocimiento y guerra", en el sentido de que determinados conocimientos que no corresponden a nuestro concepto de ciencia actual fueron utilizados como armas para ganar la guerra. Por ejemplo, en el mundo antiguo pudieron usar cadáveres y restos de animales para contaminar las aguas.

Revista de Humanidades de Valparaíso, 2019, No 14, 91-116

(c) $(1)(9)$ CC BY-NC-ND 
Los persas, griegos y romanos de la antigüedad envenenaban los pozos de sus enemigos arrojando dentro cadáveres. También en la conquista de América la llegada de los conquistadores tuvo como consecuencia la introducción de enfermedades euroasiáticas que eran nuevas en los territorios de América. Lo que no está probado es que Hernán Cortés y Pizarro llevaran deliberadamente las enfermedades para diezmar a los indígenas (García de los Ríos y Jiménez Gómez 2007, 10). También Julio Sotelo (2012) se refiere a los antecedentes históricos de las armas biológicas, remontándose al siglo XIV durante las invasiones tártaras a Crimea, en la ciudad de Kaffa, donde fragmentos de cadáveres de sujetos fallecidos por peste bubónica fueron arrojados por catapulta al interior de la ciudad en un intento por debilitar los efectivos de sus defensores. Los ingleses en el siglo XVII dieron intencionalmente cobijas impregnadas con secreciones de viruela a indios norteamericanos, cundiendo una incontenible epidemia de viruela que los diezmó con más efectividad que otra estrategia militar. Hay que decir que en esas épocas poco se sabía de las enfermedades infecciosas y se desconocían sus microscópicos agentes causales, ya que los microorganismos no fueron descubiertos hasta finales del siglo XVII y no se supo que causaban enfermedades infecciosas hasta finales del XIX. Por tanto, es difícil que anterior a estas fechas pudieran utilizarse conscientemente como armas biológicas. Eran conocimientos adquiridos por ensayo y error que se habían adquirido a través de la experiencia y que se utilizaban tanto para lo bueno (curar enfermedades) como para lo malo (la guerra).

Podemos decir que es en el siglo XX cuando estos conocimientos tienen una base científica en el sentido de conocer la causa y no solo la correlación. Este fenómeno plantea el debate de la relación entre ciencia y guerra, aunque no en todos los campos dicho debate ha aflorado de igual forma ni con la misma intensidad. En este sentido, hay que señalar que los agentes radiológicos (física) y químicos han sido los más estudiados, así como los debates correspondientes sobre la participación o neutralidad de los científicos en los conflictos bélicos. Esto no significa que la biología haya estado ausente de dichos conflictos que tuvieron lugar a lo largo del siglo XX, pero no cabe duda de que no han acaparado la misma atención que la química y, sobre todo, de la física. Wendy Barnaby (2002) señala que tras muchos decenios en los que apenas se les prestó atención, las Armas Biológicas (AB) han pasado a ser una prioridad en los planes internacionales de seguridad ${ }^{1}$.

Las dos guerras mundiales del siglo XX pusieron a prueba la difícil relación de los científicos con las empresas militares de sus países, en torno a la colaboración o neutralidad y las repercusiones para la investigación científica en sus respectivos campos. La literatura sobre armas radiológicas y químicas es abundante y los casos que se han analizado también, por lo que solamente con ofrecer un panorama de lo que han sido nos llevaría no solo a un artículo sino a un libro, como mínimo. Por tanto, los casos aportados son solo

${ }^{1}$ La participación de la biología en los conflictos bélicos la abordaremos ampliamente en el apartado 3. 
Biología y guerra: una perspectiva pragmática

Anna Estany

una pequeña muestra como ejemplos del debate en torno al papel y contradicciones de los científicos en la elaboración de dichas armas y en la colaboración con los estamentos militares de sus respectivos estados.

\subsection{El gas mostaza en la Primera Guerra Mundial}

Las primeras armas químicas se usaron en 1915 en los combates que tuvieron lugar en el frente occidental de la guerra. En 1860 el químico inglés Frederic Guthrie (18331886) sintetizó el gas mostaza, un arma de guerra química usada durante la Primera Guerra Mundial en julio de 1917 por los alemanes para impedir el ataque británico cerca de Ypern (Bélgica). El gas mostaza también se le conoce con el nombre de "Lost", por los descubridores alemanes (Lommel und Steinkopf) o "yperita", por el lugar donde se utilizó por vez primera. En 1919 se observaron - además de los efectos tóxicos sobre la piel y mucosas - una profunda leucopenia y aplasia del tejido linfoide en las personas expuestas al gas. Como consecuencia de esta barbarie, tras la gran guerra se procede a redactar el "Protocolo sobre la prohibición del uso en la guerra, de gases asfixiantes, tóxicos o similares y de medios bacteriológicos". Lo cual no significa que, por desgracia, no se volvieran a utilizar en otras guerras.

Como contrapunto y que ahonda en las paradojas con las que se enfrentan los científicos, el gas mostaza tiene un derivado en oftalmología. Con un medicamento derivado del gas mostaza desarrollado en la década de los años 20 y 30 del siglo XX, la mostaza nitrogenada, enfermos afectados de linfomas se trataron por primera vez con éxito en la Universidad de Yale (USA) en 1943. Su uso terapéutico en oftalmología lo introdujo un internista español, el Dr. Emilio Roda Pérez (1907-1983) en 1950, un hecho apenas conocido de la historia de la medicina y oftalmología española, que cuenta Antonio Bergua (2006).

\subsection{Armamento nuclear y Proyecto Manhattan}

El Proyecto Manhattan fue el nombre en clave de un proyecto científico llevado a cabo durante la Segunda Guerra Mundial por los Estados Unidos con ayuda parcial del Reino Unido y Canadá (Guerrero G. y Vega H. 2011). El objetivo final del proyecto era el desarrollo de la primera bomba atómica antes de que la Alemania nazi la consiguiera. La investigación científica fue dirigida por el físico Julius Robert Oppenheimer mientras que la seguridad y las operaciones militares corrían a cargo del general Leslie Richard Groves. El 9 de octubre de 1941, Roosevelt autoriza el desarrollo del arma atómica, dando comienzo al Proyecto Manhattan, que posteriormente se aceleraría de forma sustancial con la entrada de EE. UU. en la Segunda Guerra Mundial, hecho que ocurrió el 7 de diciembre de 1941, con el ataque de los japoneses a la costa hawaiana de Pearl Harbor. 
Biología y guerra: una perspectiva pragmática

Anna Estany

Como conclusión general, cabe destacar el Proyecto Manhattan como uno de los grandes hitos de la historia científica y armamentística ya que puso punto final a la Segunda Guerra Mundial con el bombardeo de Hiroshima y Nagasaki.

También es significativa la repercusión social que generó, ya que ocasionó miles de muertes. Además, la mayoría de las personas que participaron no conocían la finalidad del proyecto y, junto con muchos de los que sí la conocían, al ver la magnitud de dichos artefactos quedaron arrepentidos de haber participado y promovieron la no utilización de esas armas en el futuro. En cuanto a los afectados, las ciudades de Hiroshima y Nagasaki quedaron totalmente destruidas, no solo a nivel infraestructural sino a nivel poblacional, siendo significativa también la cantidad de radiación que afectaría en esas zonas durante años. A modo de reflexión personal, señalan Manuel Guerrero Giampaglia y Victoria Vega Hernández, "podemos destacar la falta de necesidad de los bombardeos ya que Japón estaba prácticamente rendida antes de que sucedieran. Además, opinamos que el hecho de que se crearan bombas atómicas "para crear la paz" supone un atraso del cual seguimos sufriendo las consecuencias actualmente" (Guerrero Giampaglia y Vega Hernández 2011, 26).

Ambos casos provocaron un debate muy interesante en torno al papel de los científicos en la guerra durante el siglo XX. Sánchez Ron (1995) examina distintas teorías sobre la guerra desde el punto de vista ético como la "concepción realista", según la cual la guerra está justificada cuando sirve al interés nacional y la "teoría de la guerra justa", según la cual la violencia nacional puede ser legítima siempre que pretenda servir fines justos y bien especificados y se rija por una serie de normas establecidas. Sánchez Ron también da cuenta de distintas manifestaciones de intelectuales, científicos, artistas, etc., por ejemplo, el manifiesto de 93 intelectuales alemanes "Llamamiento al mundo civilizado", a raíz de las repercusiones negativas que había tenido la invasión de Bélgica el 4 de octubre de 1914.

En el debate sobre ciencia y guerra son relevantes las reflexiones de Javier Ordóñez, catedrático emérito de lógica y filosofía de la ciencia, que expone en una entrevista el 12 de abril de 2019. A la pregunta de Empar Vengut Climent sobre si la relación entre los científicos y la guerra ha podido propiciar una imagen negativa de la ciencia, Javier Ordóñez responde:

Puede ser, pues es un hecho que la ciencia ha ayudado a la guerra [...] Me estoy refiriendo a las situaciones en las que el estado, como máxima autoridad social, es capaz de pedir a los científicos que dediquen sus esfuerzos a la fabricación de armas, como sucedió por ejemplo en el proyecto Manhattan. (Vengut Climent 2019)

Comenta también que esta inversión continuó durante la Guerra Fría y ejemplo de ello son las distintas generaciones de armas nucleares, en cuya construcción participaron 
Biología y guerra: una perspectiva pragmática

Anna Estany

algunos científicos relevantes reclutados por el estado para llevar a cabo el desarrollo armamentístico. Especialmente importante fue el apoyo a la física fundamental en Estados Unidos de América durante casi treinta años.

Un ejemplo de debate entre el papel de los científicos en la fabricación de armas lo expone el historiador de la física Finn Aaserud en el análisis de la actuación de la comunidad de físicos de Estados Unidos de América y el Ministerio de defensa. Aaserud en una conferencia pronunciada en la Universidad de California San Diego en 1993, titulada "In power or on tap? The making of JASON", analizaba la relación entre la comunidad de físicos y los organismos políticos y militares implicados en la Defensa de los EUA, después de la Segunda Guerra Mundial. Durante la misma, la comunidad de físicos adquirió considerables cotas de poder, dada la decisiva importancia de sus progresos científicos para el desarrollo de la guerra y la seguridad nacional de los EUA.

En la posguerra, en plena guerra fría, el lanzamiento del Sputnik el 4 de octubre de 1957 por los soviéticos creó la impresión de que la Unión Soviética iba muy por delante de los EUA en cuanto a ciencia y tecnología. La respuesta por parte de los EUA no se hizo esperar, y entre las iniciativas para recuperar la delantera científico-tecnológica está la de implicar a la comunidad de físicos, a fin de que se estableciera una estrecha colaboración entre ellos y el Ministerio de Defensa. Esto se plasmó en diversas propuestas surgidas de ambas partes para llegar a acuerdos concretos de colaboración. Uno de estos acuerdos fue el surgimiento de JASON, un proyecto que agrupaba a científicos alrededor del físico Charles Townes y que tenía como objetivo la estrecha cooperación de la comunidad científica con el Departamento de Defensa. Aaserud señala que la colaboración llegó hasta tal punto de que las líneas de investigación estaban determinadas por las necesidades de defensa, perdiendo así los físicos una buena parte de su autonomía y del predominio que habían tenido en épocas anteriores.

\section{La biología entra en guerra}

Como ya hemos indicado, la biología no quedó atrás en su papel relevante en los conflictos bélicos del siglo XX. Así empezó lo que se denomina "Guerra Biológica" (GB), como uso de organismos vivos o de sus productos para causar daños al enemigo (personas), a sus animales y a sus cosechas ${ }^{2}$. A pesar de que no tuvo la misma repercusión, como en el caso de la física y la química, en los debates ético-políticos sobre la participación de las comunidades científicas, hubo movimientos y manifiestos que cuestionaron este tipo de actividades por parte de los científicos biólogos. María Eneida de Albeida señala que "A lo largo del siglo XX hasta hoy se ha desarrollado un amplio campo de investigación tecnológica de la biología de guerra o biología militar, que trabaja en la invención y desa-

\footnotetext{
${ }^{2}$ Para las cuestiones más técnicas sobre bioterrorismo me he basado en García de los Ríos y Jiménez Gómez (2007).
}

Revista de Humanidades de Valparaíso, 2019, No 14, 91-116

(c) $(1)(9)$ CC BY-NC-ND 
rrollo de armas biológicas" (Almeida 2015, 2256). Por tanto, la biología es cada vez más importante en la biodefensa. Almeida considera que hay dos proyectos originales de "Big science", a saber: en el campo de la física el Proyecto Manhattan, con la construcción de la bomba atómica (1941); y en el campo de la biología el Proyecto del Genoma Humano para desentrañar el código genético de todos los seres vivos (1985).

Nieva Machin Osés (2010) observa cierta similitud bélica entre las armas biológicas recombinadas genéticamente y las nucleares. Ambas poseen un alto poder destructivo, sin embargo, las armas biológicas recombinadas genéticamente superarían en efectividad a las nucleares ya que éstas no atentarían contra las infraestructuras del país, sino que afectarían a la población humana, favoreciendo que el país agresor pudiera ocupar sin mayor obstáculo el área atacada siempre y cuando la población ocupante estuviera vacunada. Además, señala W. Barnaby (2002) que, empleadas en las mismas cantidades, las armas biológicas son mucho más mortíferas que las armas nucleares o las químicas y, además, son más baratas. Por tanto, podemos decir que en el siglo XX y, en concreto, en las dos guerras hubo utilización de armas biológicas pero quedaron eclipsadas por las químicas y radiológicas, al menos a nivel de repercusión social e informativa.

Así durante la Segunda Guerra Mundial se propusieron programas para la utilización de armas químicas y biológicas, tanto desde Japón como desde Alemania, aunque también los aliados llegaron a desarrollar un programa como posible respuesta a ataques biológicos por parte de Alemania, que nunca se produjo. Las investigaciones sobre AB llevadas a cabo por Gran Bretaña, Estados Unidos y Canadá estuvieron estrechamente conectadas hasta mucho después de la segunda guerra mundial. Y lo mismo podemos decir de los países como Alemania, la Unión Soviética, Japón y Sudáfrica de los que hay información de las investigaciones y experimentos en AB (Barnaby 2002, caps. 5 y 6).

El principio de la guerra fría y la guerra de Corea supuso la proliferación de armas biológicas, tanto por parte de la URSS como de la administración norteamericana. Entre las revelaciones de los tránsfugas y el posterior reconocimiento oficial, la Unión Soviética debió poseer la mayor producción y acumulación de armas biológicas que ningún país haya tenido jamás, incluyendo carbunco, viruela, peste, muermo, encefalitis equina venezolana, virus de Marburg, toxinas de varios tipos, etc., así como los medios para su dispersión (García de los Ríos y Jiménez Gómez 2007, 22). Un caso especial de análisis de guerra biológica es el bioterrorismo por ser uno de los de mayor impacto social y político a nivel mundial. El bioterrorismo es la liberación de bacterias, virus o toxinas con el propósito de causar daños a la población civil.

\subsection{Bioterrorismo y agroterrorismo}

La relación de los microorganismos con las enfermedades infecciosas fue estudiada de forma exhaustiva por la escuela francesa de Louis Pasteur y la alemana de Robert Koch. 
Biología y guerra: una perspectiva pragmática

Anna Estany

A los microorganismos causantes de las enfermedades infecciosas se los define como microorganismos patógenos y su relación con la enfermedad es la virulencia, que es el grado de patogenicidad. Entre los factores de virulencia que poseen los microorganismos destacan las toxinas producidas por las bacterias. De todas las vías de transmisión, la que siempre se ha buscado, por parte de los que están enfrentados en una guerra, ha sido la inhalación, ya que todos necesitamos respirar varias veces por minuto (García de los Ríos y Jiménez Gómez 2007, 48). Y esto tanto para las armas biológicas como para las químicas. Entre las características de un arma biológica ideal, entendida como eficiente para destruir al enemigo, pueden señalarse las siguientes: ser altamente incapacitante, ser fácil de obtener en grandes cantidades, ser fácil de introducir en armas, ser difícil de detectar al menos en los primeros momentos y con gran impacto en la salud pública, causando pánico y alarma social.

García de los Ríos y Jiménez Gómez clasifican los agentes biológicos de uso en el bioterrorismo en A, B y C con las características siguientes:

Categoría A: fácilmente diseminados o transmitidos de persona a persona, con altas tasas de mortalidad, con gran impacto en la salud pública, causantes de pánico y alarma social, y que requieren preparación especial de la Salud Pública. Entre estos agentes están la viruela, el carbunco, la peste, la tularemia y la toxina botulínica.

Categoría B: moderadamente fáciles de diseminar, con moderada morbilidad y bajas tasas de mortandad, que requieren el aumento de la capacidad de los centros de diagnóstico e incremento de vigilancia. En esta categoría están la salmonella, el cólera, las fiebres de Malta y el muermo.

Categoría $\mathrm{C}$ : se trata de patógenos emergentes que pueden ser manipulados para diseminación en masa en el futuro, debido a su disponibilidad, facilidad de producción y diseminación, así como potenciales tasas elevadas de morbilidad y mortandad. Por ejemplo, el virus Nipah causa de una encefalitis transmitida a partir de cerdos; y los hantavirus causantes de un síndrome pulmonar relacionado con roedores.

García de los Ríos y Jiménez Gómez $(2007,191)$ califican a los agentes víricos bioterroristas como el enemigo invisible por sus especiales características. A diferencia de las bacterias, los virus suelen ser organismos más difícilmente cultivables pero también más peligrosos. Este hecho es la razón por la que los gobiernos deben invertir en laboratorios de vigilancia donde equipos de profesionales mantienen sus puestos de vigías. Estos autores señalan que no conviene bajar la guardia, ya que relajar nuestro nivel de control puede facilitar un ataque bioterrorista y traernos consecuencias fatales.

Entre los virus que producen enfermedades y que, en algún grado, pueden ser objeto de bioterrorismo están los siguientes. Por un lado, las enfermedades agrupadas en torno a las fiebres hemorrágicas virales, como el ébola y la fiebre amarilla. Y, por otro, las incluidas 
en algún tipo de encefalitis: afección de los hemisferios cerebrales, tronco del encéfalo o cerebelo por un proceso infeccioso. Su causa es una patología de etiología viral: encefalitis equina venezolana (EEV) y encefalitis equina del este (EEE)/Occidental (EED) ${ }^{3}$.

Una derivada del bioterrorismo es el "agroterrorismo". Alberto Cique Moya $(2017,3)$ señala que "a lo largo de todos los tiempos la mayoría de los conflictos han sido, y serán en última instancia, por dominar los recursos hídricos y alimentarios". Por lo que "la mayoría de los programas biológicos iniciados en el siglo XX incluyen líneas de investigación específicas para conseguir agentes biológicos que afectaran a las cosechas y a los animales". Moya considera que:

[...] en este punto es importante resaltar desde un punto de vista conceptual que si a los que utilizan agentes biológicos contra las personas se les denomina bioterroristas, a los que usan, o están dispuestos a utilizar o a amenazar con su empleo, agentes biológicos contra la ganadería y la agricultura tendríamos que denominarlos agroterroristas (el objetivo último son las personas pero a través de un daño indirecto porque los primeros afectados serían las plantas o los animales). (Moya 2017, 8)

Según Moya,

[...] el agroterrorismo plantea menores retos para alcanzar la capacidad operacional de diseminación, pudiendo pasar desapercibido su uso hasta que los efectos sean devastadores. De igual forma, el agroterrorismo plantea menores dilemas éticos que el bioterrorismo al ser las consecuencias fundamentalmente económicas, considerándose que la sola amenaza de empleo tendrá efectos directos sobre la sociedad en su conjunto. (Moya 2017, 1)

Hay otra cuestión importante y distintiva de la GB que tiene que ver con la dificultad para detectar si un estado está desarrollando y desplegando armas biológicas. En el caso de las armas nucleares es relativamente sencillo, pero las $\mathrm{AB}$ son distintas y por ello no es fácil detectar si un estado las está desarrollando, o simplemente es para defenderse de posibles ataques.

Las bacterias y los virus que emplean se producen exactamente igual que los utilizados en la medicina legítima para vacunas y antibióticos. Los microorganismos con los que se fabrican las $\mathrm{AB}$ se producen con el mismo equipamiento que se encuentra en las empresas farmacéuticas, los laboratorios universitarios de biología, las fábricas de cerveza, las destilerías, las fábricas de leche, los laboratorios de diagnóstico y las instalaciones para producir vacunas. Es por ello que el equipamiento que puede emplearse tanto para fines militares como civiles se le denomina "de doble uso" y su existencia constituye uno de los mayores obstáculos para el control eficaz del desarrollo de AB (Barnaby 2002, 63).

\footnotetext{
${ }^{3}$ Para una explicación técnica de estas enfermedades, ver García de los Ríos y Jiménez Gómez (2007, cap. VII).
} 
Nos podemos preguntar qué nos depara el futuro respecto al bioterrorismo. Hacer predicciones siempre es arriesgado y más en esta cuestión. Las armas biológicas estarán siempre a punto para ser utilizadas, como cualquier otro tipo de arma. No cabe duda que, como señalan García de los Ríos y Jiménez Gómez, las llamadas para terminar definitivamente con las armas biológicas, su desarrollo y su almacenamiento están partiendo de todos los organismos internacionales, como ocurre con otros tipos de armas o como rezan los acuerdos para el caso de guerras con el trato de prisioneros, etc. Otra cosa es hasta qué punto se cumple, aunque no hay otras formas de proceder para paliar el lado malo de la investigación científica. De hecho, los descubrimientos científicos, originalmente no han sido pensados para producir el mal, aunque pueden luego ser reconducidos a este fin. La responsabilidad no sería del que descubre algo que después puede ser mal empleado, sino de los que desarrollaron un proceso para hacer daño. Y aquí volvemos al papel de los científicos en las guerras y en las contradicciones y responsabilidades morales y éticas con las que pueden encontrarse.

\section{Los nuevos derroteros de las guerras biológicas}

Los conflictos actuales en el marco de la geopolítica y geoestrategia se dirimen no solo militarmente, aunque también, sino que las formas de ejercer el poder y el dominio sobre otros países van más allá de las armas convencionales. La literatura sobre estas cuestiones es amplia por lo que vamos a centrarnos en algunos de los textos que son especialmente representativos, como es el caso del estudio sobre geopolítica y geoestrategia de Pedro Baños (2017). El acento, una vez más, está en el papel de tecnología con base en la física en primer lugar y en la química, sin apenas referencias explícitas a la biología, al menos en este estudio de Baños. No hay que olvidar que la biotecnología se ha puesto al servicio de la agricultura, para bien pero también para mal, ya que puede convertirse en una forma de agroterrorismo. Siguiendo con la relación de la tecnología y la economía Baños señala:

Respecto a los aspectos tecnológicos, la clave actual de la pugna económica es el dominio de la innovación en ciencia y tecnología. Quien no invierta en estos aspectos fundamentales debe tener claro que se convertirá en el futuro esclavo tecnológico de los países más desarrollados. (Baños 2007, 45)

Respecto al papel de la economía Pascal Lorot y François Thual afirman que la actualidad geopolítica está caracterizada por la marginación relativa del factor militar-estratégico en beneficio del económico y por la búsqueda de la potencia económica como objetivo estratégico central de los gobiernos occidentales desarrollados (Baños 2007, 63). Además del factor económico están lo que Baños denomina "armas de comunicación masiva", el ciberespacio como campo de batalla, la guerra jurídica y la religión como arma de guerra. Todos estos factores actualmente han adquirido un papel clave en la capacidad de dominio geoestratégico y geopolítico. 
En el marco de la guerra económica está el control de la producción agrícola planetaria. Baños señala que el mercado mundial del grano, cereales y leguminosas está prácticamente dominado en su totalidad por cuatro grandes corporaciones: ADM (estadounidense), Bunge (de origen brasileño con sede en Estados Unidos), Cargill (estadounidense) y Dreyfus (de origen francés y asentada en Holanda), conocidas como las ABCD. Directamente o a través de empresas subsidiarias, tienen la capacidad de establecer a escala mundial los precios de alimentos tan básicos como el arroz, el maíz, el trigo o la soja. (Baños 2007, 69). Teniendo en cuenta la importancia de los cereales como base de la alimentación, es comprensible la lucha por el dominio en este campo. Baños aporta una cita de Henry Kissinger muy significativa de la importancia de la agricultura en el dominio geopolítico. Dice así: "Controla los alimentos y controlarás a la gente; controla el petróleo y controlarás a las naciones; controla el dinero y controlarás el mundo".

Vemos pues que el papel de la economía tiene derivadas en la agricultura por lo que bien puede relacionarse con los seres vivos y su papel en la riqueza y pobreza de los territorios y, en consecuencia, con el dominio y el poder ejercido por una nación sobre otra. A partir de esta premisa entran en juego algunas ramas de la biología, como la botánica y la zoología, a través de las cuales la relación entre biología y guerra queda patente. Según la RAE, la biología es la ciencia que trata de los seres vivos considerando su estructura, funcionamiento, evolución, distribución y relaciones. A veces se habla de ciencias biológicas como un concepto más amplio pero ligado a "lo bio" en el sentido de vida. Y aquí entrarían campos como la biología marina, la botánica, la zoología, etc. De todos estos campos vamos a centrarnos en la botánica y en la zoología por su papel relevante en los ejemplos que constituyen armas para dirimir conflictos.

La botánica es la rama de la biología que estudia los vegetales a todos los niveles: descripción, clasificación, distribución, funcionamiento, reproducción (Portela 2016). Para el objetivo de este trabajo es relevante la distinción entre botánica pura y aplicada, como indica Portela (2016):

La botánica pura se encarga del estudio de los vegetales como ciencia básica y la botánica aplicada estudia los vegetales para su explotación comercial, ya sea forestal, farmacéutica, alimentaria, etc. [...] Los vegetales, especialmente los cereales y las legumbres, son la base de la alimentación humana, de ahí la gran importancia que se dio a su investigación ya desde la antigüedad.

Portela señala que la botánica tiene importantes usos en el día a día, estudiando compuestos presentes en los vegetales y que se utilizan para desarrollar medicamentos, desde el ácido salicílico (que se emplea en las aspirinas y ya era conocido por civilizaciones antiguas, que consumían corteza de abedul para beneficiarse de esta substancia) a la morfina o la cafeína. De hecho, la selección de semillas y la hibridación entre variedades botánicas se han utilizado desde los albores de la agricultura para mejorar los cultivos, con espectaculares resultados. Por ejemplo, algunas especies silvestres como el maíz o 
Biología y guerra: una perspectiva pragmática

Anna Estany

el trigo resultan difícilmente comestibles, por lo que hizo falta un proceso de selección para que las plantas produjeran granos cada vez mayores. Para Portela (2016), "la botánica es una ciencia fascinante con numerosas aplicaciones para nuestra sociedad y está relacionada con otras ramas de la biología como la ecología, la taxonomía, la genética o la bioquímica".

La zoología, como rama de la biología, se dedica al estudio de los animales. La palabra

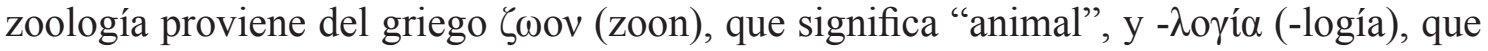
traduce "estudio" o "ciencia". El principal objetivo de la zoología es el examen de la descripción morfológica y anatómica de las diversas especies animales: su reproducción, desarrollo, comportamiento y distribución. Para el tema de este trabajo es especialmente relevante la zoología aplicada que se encarga del estudio de los animales con resultados económicos o prácticos. En este sentido, la zootecnia trata de la cría y multiplicación de los animales, así como de la producción de sus derivados, como la leche, teniendo en cuenta el bienestar del animal.

Como en la mayoría de los casos las aplicaciones de los conocimientos científicos comportan beneficios en muchos ámbitos de la sociedad pero también pueden utilizarse para perjudicar tanto al medio ambiente como a colectivos y naciones que se quiere destruir o dominar. En una palabra, puede constituir un arma de guerra. Vamos a examinar algunos de estos casos en que ramas de la biología como la botánica y la zoología, en ambos casos aplicadas, han sido utilizadas como arma de guerra, directa o indirectamente. Los casos que señalamos a continuación son fruto de conflictos, algunos enmarcados en lo bélico y militar, pero las consecuencias agropecuarias no son consecuencias de las armas biológicas sino de políticas y ataques militares, que ocasionan perjuicios muy serios para cosechas y ganado y, en último término, para los habitantes de determinadas regiones.

\subsection{Las "guerras" del campo: COAG"}

La Coordinadora de Organizaciones de Agricultores y Ganaderos (COAG) tiene su referente histórico más remoto en las movilizaciones campesinas que se produjeron a finales de la década de los 60 y principios de los 70. En aquellos años las reivindicaciones se relacionaban fundamentalmente con los precios agrarios. Era el tiempo de las "guerras" del pimiento, del maíz, de la leche, de la patata, etc.

La experiencia asociativa que supusieron estos movimientos espontáneos sirvió para que en los últimos años del régimen franquista se crease un embrión de lo que sería durante la transición la configuración de lo que más tarde sería la COAG. Los agricultores

\footnotetext{
${ }^{4}$ https://www.centroestudioscervantinos.es/ramas-de-la-biologia/

${ }^{5}$ http://www.coag.org/
} 
Biología y guerra: una perspectiva pragmática

Anna Estany

que participaron en aquellas protestas y reivindicaciones por los precios descubrieron su propia capacidad organizativa y la escasa o nula representatividad de las llamadas entonces "Hermandades Sindicales de Labradores y Ganaderos".

Las Uniones recién creadas no defendían ya una mera cuestión coyuntural como fueron las "guerras" por los precios, que pasan a un segundo plano, sino que ahora se plantean y reivindican un modelo productivo para el campo basado en la Explotación Familiar Agraria (EFA), así como la defensa del Agricultor a Título Principal (ATP).

El entrecomillado de guerra es de la propia organización COAG, ya que son conscientes de su utilización como analogía o metáfora de los conflictos bélicos. Pero, tal como hemos indicado, los conflictos no se dirimen solo militarmente, aunque las consecuencias pueden ser también muy perjudiciales, cuando no destructivas, de las poblaciones implicadas en dichos conflictos. En el caso de las denominadas "guerras del campo" se juega la supervivencia y bienestar de las poblaciones afectadas, pero también el abastecimiento alimenticio del conjunto de la sociedad.

\subsection{El papel de la agricultura y la ganadería en el conflicto entre Palestina e Israel}

El conflicto entre Palestina e Israel se juega, aunque no sólo, en el dominio de los productos agrícolas y ganaderos. Digo que "no sólo" porque tiene una baza muy importante en lo militar, pero incluso las acciones militares tienen consecuencias inevitables en la agricultura y en la ganadería. Esta circunstancia en la que convergen lo bélico y lo agroganadero hace que este caso sea muy ilustrativo del carácter multifactorial de los conflictos de nuestra época. El texto "Cultivando injusticia: El comercio internacional con las compañías agrícolas israelíes y la destrucción de la agricultura palestina"6, publicado por organizaciones agrícolas y de la sociedad civil palestina en febrero del 2013, da cuenta de ello.

Para los palestinos, la agricultura es mucho más que la producción de olivos, cítricos y otros productos frescos o la cría de ganado. La agricultura está ligada a la identidad del pueblo palestino, a su historia y a la resistencia a la ocupación ilegal israelí. La soberanía alimentaria ha sido definida por los campesinos internacionales del movimiento Via Campesina como sigue:

La soberanía alimentaria es el derecho de los pueblos a definir su propia alimentación y su propia agricultura; a proteger y regular su producción agrícola doméstica y a negociarla para lograr objetivos de desarrollo sostenible; a determinar la extensión de lo que ellos quieren para ser autosuficientes; a restringir el "dumping" de productos en sus mercados;

\footnotetext{
${ }^{6}$ https://www.stopthewall.org/sites/default/files/Injusticia\%20Agricola.pdf_
} 
Biología y guerra: una perspectiva pragmática

Anna Estany

y a dar a las comunidades de base de los pescadores locales la prioridad del control del uso y los derechos de sus recursos acuáticos. (Organizaciones agrícolas y de la sociedad civil palestina 2013,5)

Esta soberanía se ve cuestionada por las acciones de Israel sobre Palestina. Entre los datos que nos ofrecen las organizaciones agrícolas podemos destacar las que afectan a las cosechas, a la pesca, al agua y al comercio internacional.

\subsubsection{Cosechas}

- En mayo del 2009 las tropas israelíes incendiaron las cosechas palestinas a lo largo de la frontera de Gaza con Israel. Fueron destruidas más de 200.000 metros cuadrados de cosechas, incluyendo trigo y cebada que ya estaban listas para recolectar, así como frutas y verduras, olivos y granados.

- Las repetidas ofensivas militares israelíes contra Gaza y sus años de asedio han llevado a una caída dramática en el número de palestinos empleados allí en el sector agrícola, reduciendo la producción y los ingresos de los granjeros palestinos, dejando al 80\% de los palestinos en Gaza dependientes de la ayuda alimentaria ${ }^{7}$.

- La destrucción de los medios de vida palestinos y la negación de suministros y bienes esenciales a los granjeros de Gaza son herramientas usadas conscientemente por los que diseñan las políticas israelíes. Un alto funcionario israelí describía la política israelí en Gaza diciendo que "la idea" es "poner a los palestinos a dieta, pero no hacerlos morir de hambre". El gobierno israelí calculó el número mínimo de calorías que necesitan los 1.500.000 habitantes de Gaza para evitar la malnutrición y esos números fueron usados para determinar la cantidad de comida que se permitirá entrar cada día ${ }^{8}$. A pesar de ello muchos granjeros palestinos continúan cuidando sus tierras agrícolas en partes de las zonas de defensa a pesar del gran riesgo de muerte o de heridas graves.

\footnotetext{
${ }^{7}$ La referencia que ofrecen para esta información es: Israel reduce el suministro de trigo a la Franja de Gaza: La seguridad alimentaria en Gaza en gran riesgo mientras continua el asedio israelí (2010). Centro Al Mezan para los Derechos Humanos. Obtenido de http://www.mezan.org/en/details.php?id=11120\&ddname $=\&$ id_dept $=9 \& p=$ center

${ }^{8}$ La referencia que ofrecen para esta información es: Cook, J. (2012). Israel's starvation diet for Gaza. 8. The Electronic Intifada. Obtenido de http://electronicintifada.net/content/israels-starvation-diet-gaza/11810.
} 


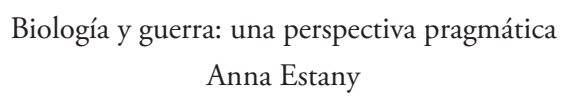

- Los olivos juegan un papel importante muy especial en la economía palestina y en la identidad palestina en general. Israel por otra parte es muy consciente de eso; el ejército israelí y los colonos fanáticos conjuntamente han desarraigado, quemado y destruido cerca de 1.500 .000 olivos desde el $2001^{9}$.

Una consecuencia del decaimiento de la agricultura es que, como la zona de tierra disponible para las granjas se encoge, los palestinos que quieren trabajar en la agricultura están obligados a moverse a las zonas urbanas para trabajar, lo que al mismo tiempo reduce el tamaño de las comunidades agrícolas y el número de palestinos con conocimientos y experiencia en las faenas agrícolas.

\subsubsection{Pesca}

Israel también ha aplicado un área de defensa naval. A pesar de los Acuerdos de Oslo que declaran que los palestinos tienen el derecho de pescar hasta las 20 millas náuticas de la costa de Gaza, Israel impuso un límite de tres millas en junio del $2007^{10}$. Dado que están obligados a pescar en esas aguas tan poco profundas, los pescadores palestinos solo pueden pescar principalmente peces pequeños que han sido contaminados por la salida inadecuada de las instalaciones de tratamiento de aguas residuales.

\subsubsection{Agua}

Cisjordania es muy rica en recursos acuíferos, pero Israel ilegalmente controla todas las fuentes de agua en Cisjordania, incluyendo el Río Jordán, y saca casi el 90 por ciento anualmente del agua necesaria de sus ricos acuíferos, dejando a los granjeros palestinos con un chorrito ${ }^{11}$. Amnistía Internacional ha acusado a Israel de privar a los palestinos de su acceso al agua "como un medio de expulsión"12.

La zona del Valle del Jordán tiene unos 2,400 km2, y está ubicada el Este de Cisjordania, ocupando el $28.5 \%$ de su área. Con su clima favorable, tierra fértil y un buen suministro de agua, el Valle del Jordán es la principal zona agrícola de Cisjordania y en total forma los territorios palestinos ocupados.

\footnotetext{
${ }^{9}$ La referencia que ofrecen para esta información es: One Million Trees Campaign (MTC) II, http://29. apnature.org/en/content/one-million-trees-campaign-mtc-ii.

${ }^{10}$ La referencia que ofrecen para esta información es: PCHR 19. 2011 Annual Report. (2011). Palestinian Centre for Human Rights, p. 29.

${ }^{11}$ La referencia que ofrecen para esta información es: Assessment of Restrictions on Palestinian Water Sector. Development. (2009). World Bank.

${ }^{12}$ La referencia que ofrecen para esta información es: Troubled waters: Palestinians denied fair access to water 34 (2009). Amnesty International.
} 
Biología y guerra: una perspectiva pragmática

Anna Estany

\subsubsection{Comercio internacional}

Las compañías agrícolas israelíes como Mehadrin y Hadiklaim participan en la colonización de la tierra palestina y de sus recursos y se aprovechan del continuado asedio a Gaza. Están entre los primeros beneficiados de la destrucción de la agricultura palestina. A los productores palestinos a veces no les queda más opción que exportar a través de las compañías exportadoras israelíes, que a veces etiquetan los productos palestinos como "Hecho en Israel".

El conflicto continúa y las denuncias a acciones de Israel que afectan a la agricultura también. Así lo explica Juan Carlos Sanz en un reportaje sobre "La 'guerra herbicida' de Israel arrasa cultivos en Gaza" el 21 de julio de 2019 en El País. Una investigación constata que las fumigaciones ordenadas por el Ejército israelí afectan al enclave palestino. El perímetro interior de la frontera de la franja de Gaza con Israel se ha convertido en un terreno yermo donde los francotiradores militares pueden hacer blanco con facilidad. El Ejército ha ordenado 30 fumigaciones aéreas con agentes herbicidas en los últimos cinco años. En el reportaje se alude a Arquitectura Forense - una agencia multidisciplinar asentada en Londres que recurre a técnicas arquitectónicas, legales y de los peritos forensesque reconstruye en el informe "La guerra de herbicidas en Gaza" la destrucción sufrida en tierras cultivables y cosechas, así como los daños potenciales que se derivan para la salud humana, en la franja costera. Las concentraciones de productos químicos tóxicos superan los niveles permitidos por la Unión Europea, y uno de los pesticidas utilizados contiene glifosato, sospechoso de ser cancerígeno según la Organización Mundial de la Salud. Tenemos un caso de convergencia de armas químicas y consecuencias en al campo de la botánica y de la salud. Podríamos decir que intervienen las ciencias biomédicas como consecuencia de los conocimientos químicos.

Como apuntamos al principio en el conflicto entre Palestina e Israel confluyen desde el militar hasta el comercial. El dominio de Israel sobre Palestina se ejerce atacando la soberanía alimenticia que afecta a la agricultura, la ganadería y la pesca, con consecuencias comerciales y, en último término, económicas.

\subsection{Corea y Japón}

Baños aporta un caso muy relevante para comprender un nuevo episodio de la guerra económico-agrícola. Durante el siglo XIX, Corea era un "reino ermitaño", contrario a establecer relaciones diplomáticas y comerciales con los países occidentales. Corea prefería mantener una alianza con una China que también pugnaba por librarse de la injerencia occidental. La primera guerra chino-japonesa (1894-1895) fue motivada principalmente por el dominio de Corea, alzándose Tokio con la victoria. En 1897, el emperador Gojong proclamó el Gran Imperio de Corea, que significaba dejar de ser el apéndice de China que llevaba siendo desde 1636. 
Biología y guerra: una perspectiva pragmática

Anna Estany

Japón, convertida en potencia industrial, se anexionó el Imperio de Corea en 1910 para explotarlo económicamente. El gobierno nipón promovió la llegada a la península coreana de agricultores y pescadores japoneses, a los que hacía entrega gratuita de tierras o se las vendía a un precio simbólico. Mientras los coreanos pasaban hambre, los japoneses se llevaban la mayor parte de las cosechas de arroz para alimentar a su propia población. Los japoneses consideraban a los coreanos como étnicamente inferiores y no se reprimieron a la hora de aplicar sobre ellos las mayores crueldades (Baños 2007, 81).

Durante la Segunda Guerra Mundial, aunque los datos varían según las fuentes, las cifras son escalofriantes. En los tres años de guerra se pudieron lanzar unas 650.000 toneladas de bombas sobre Corea del Norte. (....) Cuando se acabaron los objetivos urbanos, comenzaron a bombardear pantanos y presas, lo que provocó la inundación de granjas y destruyó las cosechas. En comparación, Estados Unidos arrojó más toneladas de bombas en Corea del Norte que en todo el Pacífico durante la Segunda Guerra Mundial, y se destruyeron más ciudades que en Alemania o Japón. Una guerra que empezó militarmente con conocimientos, fundamentalmente, de la física, la química y la tecnología, terminó con consecuencias muy graves para la agricultura y la ganadería.

\section{5. ¿Podemos hablar de una filosofía de la guerra?}

La filosofía se genera como consecuencia de la capacidad recursiva del Homo Sapiens. Así podemos pintar un cuadro, escribir una novela o construir una teoría y al mismo tiempo reflexionar sobre ello y así hasta el infinito. Al menos teóricamente la capacidad recursiva del ser humano no tiene límites, aunque luego los filósofos delimiten sus niveles de reflexión (Estany 2006). Desde este punto de vista la filosofía sería un saber adjetivo, no sustantivo, es decir, "filosofía de". Así tenemos la ética, la estética, la filosofía política y la filosofía de la ciencia como reflexiones sobre sistemas morales, estéticos, políticos y científicos, respectivamente.

Hay que aclarar que la filosofía no es la única actividad que se sitúa en este segundo nivel de conceptualización, la musicología, las distintas críticas (literaria, de arte etc.) o los comentaristas (deportivos, de modas etc.) son otras actividades de segundo orden. Ninguna de estas funciones supone la habilidad en la actividad que se está analizando: así pues un musicólogo no necesariamente toca algún instrumento, ni un crítico literario escribe novelas. Pero sí necesita tener conocimiento del objeto que está analizando, por ejemplo, un musicólogo tiene que saber leer una partitura y un crítico literario saber cuál es la estructura de una novela. El filósofo de la ciencia no tiene por qué ejercer de científico: toma los productos científicos para analizarlos. Conclusión, no solamente podemos hablar de filosofía de la guerra, sino que es uno de los retos de la filosofía en el mundo actual. 
Biología y guerra: una perspectiva pragmática

Anna Estany

La filosofía de la ciencia a lo largo del siglo XX ha estado centrada en el análisis de las ciencias puras, cuyo objetivo es la descripción y explicación del mundo natural y social. Sin embargo, en la actualidad y, muy especialmente, después de la II Guerra Mundial, la imbricación entre ciencia y tecnología y la importancia de la ciencia aplicada ha hecho emerger una serie de campos disciplinares como las ingenierías, la medicina, las ciencias de la información y de la educación, etc., dando lugar a las denominadas "ciencias de diseño", entre las que estaría la ciencia de la guerra. No cabe duda de que estas reflexiones suponen una distinción entre ciencia pura y ciencia aplicada y entre ciencia y tecnología, que algunos filósofos, sociólogos y científicos cuestionan. Por ejemplo, Javier Echeverría (2003) introduce en sus propuestas la idea de "tecnociencia", como campo de interrelación entre ciencia y tecnología (Estany 2005). Sobre esta cuestión podemos decir que, a pesar de que en la práctica la ciencia y su aplicación interaccionan, conceptualmente no solo pueden distinguirse, sino que no hacerlo lleva a la confusión a la hora de tomar decisiones en las que la ciencia tiene un papel relevante.

La conclusión de estas primeras consideraciones sobre el papel de la filosofía en el análisis de las cuestiones sobre la biología aplicada en todas sus ramas va tomando cuerpo. A veces, en la comunidad filosófica, pero no solo, se plantea la muerte de la filosofía que podría ser sustituida por la ciencia y la tecnología, pero si entendemos el hacer filosófico como una reflexión sobre cualquier actividad intelectual, la muerte de la filosofía solo se produciría por la extinción de la humanidad. Lo que hay son nuevos retos, nuevas formas de abordarlos, pero así como la ausencia de planes para una persona individual significa el fin de la vida también aquí el fin de la filosofía sería el fin de la capacidad recursiva como humanos.

Una vez constatada la relevancia de la filosofía vamos a centrarnos en aquellas cuestiones que mejor nos pueden iluminar en el tema central de este trabajo, a saber: la relación entre ciencia y guerra desde la vertiente pragmática de la biología. Como modelos teóricos para abordar dichas cuestiones vamos a analizar la relación entre ciencia pura y aplicada, en el marco de las ciencias de diseño y sus correspondientes metodologías. Finalmente, veremos lo que la ética puede aportar a un fenómeno tan complejo como importante para la humanidad.

\subsection{Ciencia pura y aplicada}

La distinción entre ciencia pura y aplicada, así como entre ciencia y tecnología ha sido motivo de debate en filosofía de la ciencia. De forma especial el papel relevante de lo que se ha denominado "big science", en el sentido de la ciencia que requiere de grandes infraestructuras para poder llevarse a cabo, desde tecnológicas hasta las organizativas y financieras. En este sentido, son interesantes las reflexiones de Nils Roll-Hansen (2009, 8) quien señala que "Esta ambigüedad genera debates confusos, por ejemplo en relación con los niveles adecuados de financiación o de utilidad social de la inversión en la in- 
Biología y guerra: una perspectiva pragmática

Anna Estany

vestigación científica $\mathrm{y}$, finalmente, se toman decisiones poco adecuadas". Y añade lo siguiente: "Parece difícil negar que había una diferencia "moralmente significativa" entre la investigación de Hahn-Meitner sobre la reacción en cadena del uranio 236 y el proyecto Manhattan de la construcción de una bomba atómica" (Roll-Hansen 2009, 26). Por el contrario, marcar las diferencias puede reportar clarificación para la política de la ciencia, ya que "estas diferencias podrían mejorar las posibilidades de desarrollar una política de la ciencia para servir a la sociedad en su conjunto y no solo a los intereses particulares de determinados grupos, ya sean empresas privadas, movimientos políticos, religiones particulares, la comunidad científica, u otros" (Roll-Hansen 2009, 2; Estany y Herrera 2016, cap. 1). Aplicado a la investigación en el campo de la biología esta distinción es sumamente relevante por el doble uso que puede hacerse de los agentes biológicos y la frágil línea que separa el desarme versus el desarrollo o la defensa versus la ofensa.

Una de las posibles razones de porqué se cuestiona la distinción entre ciencia pura y aplicada es por la imbricación que en la actualidad existe entre la investigación básica, la utilización de ésta por las ciencias de diseño y la construcción de artefactos (tecnología) para cambiar la realidad. Esta interrelación no es un fenómeno estrictamente nuevo pero sí lo es la celeridad con la que se produce. M. Kranzberg, historiador de la tecnología, señala en "The unity of science-technology" (1967) que pasaron 1700 años desde que la máquina de vapor fuera diseñada en Alejandría hasta que Watt la hizo funcionar, el principio de fotografía tardó en llevarse a la práctica 200 años desde que fue esquematizado por Leonardo, el motor eléctrico tardó 40 años, la energía nuclear 5 años, el transistor 5 años, los plásticos transparentes 2 años y los rayos láser 18 meses. Esto, dice Kranzberg, apoya la tesis de que la asociación de la ciencia (que quiere saber el "porqué") y la tecnología (que quiere saber el "cómo") produce una reacción en cadena de descubrimiento científico e invención tecnológica. Podemos concluir que entre ciencia pura y aplicada y tecnología hay convergencia en la práctica, pero diferencias conceptuales importantes.

\subsection{Las ciencias de diseño}

Las "ciencias de diseño", denominadas así por H. Simon (1996) y analizadas desde la filosofía por I. Niiniluoto (1993), son el resultado de la cientificación y mecanización de las artes en el sentido de habilidades para resolver problemas prácticos. Las ingenierías, la medicina y las ciencias de la educación y las de la información son ejemplos de este tipo de disciplinas. Consideramos que las propuestas de Simon y Niiniluoto constituyen marcos teóricos idóneos para una aproximación racionalista a la perspectiva pragmática de la ciencia y, en concreto, a lo que podemos denominar "filosofía de la guerra".

Simon (1996) señala que el modelo tradicional de ciencia ofrece una imagen engañosa de campos como la ingeniería, medicina, arquitectura, economía, educación, etc., que están interesadas en el "diseño", en el sentido de propósito o meta a conseguir, es decir, no tienen como objetivo saber cómo son las cosas sino cómo tienen que ser para

Revista de Humanidades de Valparaíso, 2019, No 14, 91-116

(c) $(1)(9)$ CC BY-NC-ND 
conseguir determinados fines. A esta lista de ciencias de diseño podemos añadir la ciencia de la guerra. Niiniluoto, a partir de las ideas centrales de Simon, distingue entre ciencias descriptivas, ciencias de diseño y tecnología. Las primeras nos dicen cómo es el mundo, las segundas qué debemos hacer para transformarlo y la tecnología es el instrumento para esta transformación.

Desde el campo de las ciencias aplicadas se ha cuestionado la metodología clásica de la ciencia porque no encaja con su forma de proceder. Así, el método científico estándar, consiste en poner a prueba una hipótesis y si ésta se confirma a través de una prueba experimental se añade al conocimiento existente hasta que haya contraejemplos que la cuestionen. Sin embargo, el diseño de cualquier artefacto, proyecto, etc. es más complejo, siendo el resultado de dos entradas, la científica y la no técnica o de reconocimiento de las necesidades. La entrada científica incluye el conocimiento existente relevante para el diseño de lo que queramos producir. En el reconocimiento de la necesidad están implícitos los factores socioeconómicos para los que los valores contextuales son relevantes para los objetivos propuestos. Sin embargo, las necesidades no son inocuas, sino que tienen consecuencias y favorecen a colectivos distintos. Cualquier decisión supondrá progreso en algún aspecto, pero será percibido de forma distinta por los diversos sectores de la sociedad.

En el caso de la guerra biológica, por un lado, tendríamos los factores científicos que serían los conocimientos aportados por la biología, desde la biología molecular hasta la botánica y la zoología; por el otro, los factores contextuales, desde los geopolíticos a los económicos, serían los objetivos que se pretende alcanzar. Y en el caso de las armas biológicas habría de considerar desde los terapéuticos hasta los defensivos y ofensivos. El diseño final sería el resultado de la conjunción de todos estos factores. Cuáles priorizar o hacer prevalecer tendrá que ver con valores no solo científicos sino ético-morales, que es la siguiente cuestión que nos podemos plantear desde la reflexión filosófica.

\subsection{Dilemas éticos de la investigación biológica}

Los dilemas éticos no son exclusivos de la investigación en biología, pero sí que es especialmente relevante por el hecho de que la mayoría son de doble uso. También tienen usos distintos la investigación en física y en química, pero en biología la línea está más difuminada. El caso de la comunidad de físicos y el ministerio de defensa de los EUA, al que nos hemos referido en el apartado 2, analizado por Finn Assaraud es una muestra de estas contradicciones. Para la biología, vamos a referirnos a un caso descrito por Wendy Barnaby ${ }^{13}$ que muestra dichas contradicciones y nos da elementos para la reflexión ética.

\footnotetext{
${ }^{13}$ Este caso está ampliamente explicado en Barnaby (2002, cap. 10).
} 
Biología y guerra: una perspectiva pragmática

Anna Estany

En 1996 un doctorando de la Facultad de Medicina de Illinois acudió al catedrático de Política y Ética Sanitarias Marc Lappe para consultarle un dilema que se le había planteado. El joven se había especializado en biología marina. Era una autoridad en las propiedades de la saxitoxina, una de las sustancias más tóxicas que se conocen. Producida por las algas, la saxitoxina puede ser letal para quienes ingieren marisco contaminado. En su forma purificada, puede matar a una persona en quince minutos si se le introduce en el cuerpo mediante un proyectil.

El establecimiento de Fort Detrick, Maryland, donde en aquel momento se llevaba a cabo una investigación ofensiva y defensiva sobre la GB, había ofrecido una beca posdoctoral al joven científico. Éste consultó al profesor Lappe si debía aceptar. Sabía que en los laboratorios de Fost Detrick encontraría la mejor infraestructura posible para realizar sus investigaciones, consistente en estudiar las consecuencias de la ingestión de saxitoxina. Pero le preocupaba la posibilidad de que parte de su trabajo se incorporase al programa ofensivo. ¿Debía aceptar la beca?

El profesor Lappe argumenta (Smith 1996, 2) que el joven no debería haber aceptado la beca. Aunque su propósito fuera mejorar un problema que afectaba a la salud pública, sabía que quienes le financiaban los estudios se dedicaban a la investigación bélica y que, por tanto, sus resultados podrían emplearse para fines bélicos. Imaginar que no se es responsable de los fines a los que otros aplican tu trabajo, dice Lappe, es "basarse en la premisa de que el conocimiento científico es moralmente neutro y de que los eventuales usos que se le den no pueden ser averiguados ni por el más avisado de los investigadores" (Smith 1996, 49).

Robert L. Sinsheimer, catedrático de biología de la Universidad de California, Santa Bárbara, también ha explicado elocuentemente porqué las responsabilidades de los científicos son mayores. Las armas biológicas, afirma Sinsheimer, "representan una perversión de los mayores logros acumulados a lo largo de las generaciones en el campo del esfuerzo y el conocimiento científicos. Su utilización despojaría de sentido a las vidas de los científicos de todos los tiempos" (citado por Barnaby 2002, 197). A pesar de estas consideraciones de algunos científicos, según Barnaby, son pocos los científicos en activo a quienes les interesan estos asuntos. Muchos piensan que la GB es un asunto periférico, sobre todo ahora que se debe consagrar tanto tiempo a conseguir fondos para las investigaciones y que, por el hecho de ser científico no se sienten responsables de advertir de los peligros de los nuevos avances de educar al público.

Barnaby también hace referencia a la bióloga celular Sue Mayer que en 1988 daba clases en la Escuela de Ciencias Veterinarias de la Universidad de Bristol. Uno de sus colegas estaba a punto de aceptar fondos del Ministerio de Defensa para llevar a cabo una investigación. Sue Meyer explicó los motivos porqué ella y varios de sus compañeros se oponían a aceptar dichos fondos. Meyer trabajaba con un equipo denominado "Grupo Aerobiología", cuyo objeto de estudio eran los caballos ya que es un buen modelo para 
extrapolarlo a los humanos. Algunos compañeros estaban estudiando lo que sucede cuando se inhalan microorganismos y cómo provocan las enfermedades, así como la manera de determinar qué dosis resulta infecciosa. Y ésta era la investigación que interesaba al Ministerio de Defensa, a fin de conocer el funcionamiento de los pulmones y la manera en que se operaba ese proceso de reparación, y así saber cuántos microorganismos son necesarios para provocar una enfermedad. Evidentemente, comprender cómo los pulmones reparan los daños subletales también sería útil para propósitos civiles. Por ejemplo, en lo relacionado con la higiene del aire, ya que se puede creer que no hay bacterias infecciosas en el aire cuando en realidad sí las hay. Averiguarlo sería de gran ayuda, pongamos por caso, en la sala de infecciosos de un hospital o en un establo.

Por el hecho de que esta investigación la financiara el Ministerio de Defensa, generaba a Sue Meyer y a su equipo una cierta desconfianza. De hecho, el Ministerio de Defensa solo estaba autorizado a investigar en cuestiones de defensa, pero se tenía miedo de que esta investigación no fuera a utilizarse para una GB. Al final la investigación se llevó a cabo, pero Meyer se opuso y dejó la Universidad ya que las autoridades académicas aceptaron llevar a cabo esta investigación financiada por el Ministerio de Defensa. Barnaby cuenta que Meyer se convirtió en directora científica de Greepeace.

\subsection{1 ¿Qué hacer?}

Los dilemas éticos respecto a la ciencia interpelan, de manera especial, a los científicos pero no podemos descargar sobre ellos toda la responsabilidad. Actualmente, la difusión de los conocimientos científicos ha crecido considerablemente y también los colectivos que desean que se tenga en cuenta su opinión, por tanto, es la sociedad en su conjunto que tiene que intervenir en las políticas científicas diseñadas por los gobiernos. Los nuevos retos de la ciencia nos atañen a todos.

Una de las cuestiones es bajo qué criterios podemos tomar una decisión como la que se enfrentaron el doctorando de la Facultad de Medicina de Illinois y Sue Mayer como responsable del proyecto de investigación del Grupo Aerobiología. Como en cualquier dilema ético, soluciones salomónicas no existen y entrar a juzgar moralmente decisiones personales nos adentramos en un terreno resbaladizo que plantea nuevos dilemas de hasta qué punto podemos intervenir en las decisiones personales de otros. Hay otro elemento que forma parte esencial de la investigación en biología y es el doble uso de dichas investigaciones, lo cual complica la decisión y su moralidad. El caso de Sue Mayer es una muestra de ello.

Como proyección de futuro para abordar la responsabilidad como sociedad podemos apuntar algunas propuestas, posiblemente todas necesarias pero ninguna suficiente. Una mayor concienciación de la sociedad de las posibilidades positivas y negativas de una misma investigación científica y, en consecuencia, mayor responsabilidad de cada uno de 
Biología y guerra: una perspectiva pragmática

Anna Estany

nosotros. Es necesario que esta participación se institucionalice, como se ha hecho en el caso de los comités de bioética en los hospitales y en los laboratorios que investigan con animales. Esto significa que debería haber comités de ética en todas las etapas del proceso de investigación, desde el laboratorio hasta sus aplicaciones. Todo ello tanto a nivel nacional como internacional. La educación y la difusión de la ciencia no debe ser ajena a los dilemas éticos que hemos planteado. Todo este entramado daría más confianza a los jóvenes doctorandos a la hora de decidir si aceptan determinado tipo de investigación. La fuente de financiación es importante pero no puede centrarse solo en el Ministerio de Defensa, al menos mientras no haya una desmilitarización universal. El fomento de la cultura de la paz tiene que ser el telón de fondo de la perspectiva ética de la ciencia.

\section{Conclusiones}

El papel de la biología en la guerra y en los conflictos, sean o no militares, ha sido cada vez más importante a lo largo del siglo XX y continua en la actualidad.

Es cada vez más relevante la intervención de distintas ramas de la biología como la botánica y la zoología, ambas aplicadas, por su implicación en la soberanía alimenticia que puede provocar hambruna, con lo cual constituye un arma de guerra, aunque no militar. Es lo que se ha denominado "agroterrorismo".

Las especiales características de las armas biológicas hacen que puedan ser accesibles por grupos terroristas fuera de cualquier tipo de control político y de acuerdo que pueda ser un freno en la utilización de estas armas.

Aunque con un cierto retraso respecto a la física y a la química, la biología también ha entrado en el debate sobre el papel de los científicos y su colaboración con los estamentos militares en los conflictos bélicos. Uno de los factores, aunque no el único, que hace especialmente difícil la reflexión sobre la responsabilidad de los biólogos en la investigación en este campo es el doble uso de la mayor parte de los proyectos que se llevan a cabo. La línea que separa lo que puede ser defensa de lo que es ofensiva no siempre está meridianamente clara.

A pesar de ello, la reflexión filosófica sobre estos temas puede ayudar a esclarecer algunas de las cuestiones más espinosas. En este sentido, la distinción conceptual entre ciencia pura y aplicada a la vez que su convergencia en la práctica ayuda a dirimir cuestiones complejas respecto a la responsabilidad en el campo político de la ciencia. Como modelos teóricos para la ciencia aplicada, la idea de ciencias de diseño y sus correspondientes metodologías constituyen formas de filosofía aplicada.

En cuanto a la responsabilidad de los científicos en la guerra, la ética puede abrir caminos a fin de paliar las posibles consecuencias más destructivas de la investigación científica. Como dijimos al principio, la reflexión ética se ha institucionalizado en el ámbito de la salud a través de comités de bioética en muchos centros hospitalarios y en 


$$
\begin{aligned}
& \text { Biología y guerra: una perspectiva pragmática } \\
& \text { Anna Estany }
\end{aligned}
$$

los laboratorios que trabajan con animales a fin de que se respeten las normas que velan por su bienestar. Es hora de que estos comités se instalen en todas las instancias políticas nacionales e internacionales que establecen las reglas de juego en los conflictos y toman decisiones que afectan a personas inmersas en dichos conflictos.

\section{Referencias bibliográficas}

Almeida, M. E. de (2015). A permanente relação entre biologia, poder e guerra: o uso dual do desenvolvimento biotecnológico. Ciência saúde coletiva, 20(7): 2255-2266.

Aznar Fernández-Montesinos, F. (2014). Filosofía de la guerra. Arbor, 190(765): a096. doi: http:// dx.doi.org/10.3989/arbor.2014.765n1003

Baños, P. (2017.) Así se domina el mundo. Desvelando las claves del poder mundial. Barcelona: Planeta.

Barnaby, W. (2002). Fabricantes de epidemias. El mundo secreto de la guerra biológica. Madrid: Siglo XXI.

Bergua, A. (2006). El uso pionero de la mostaza nitrogenada por Emilio Roda Pérez en el tratamiento de las uveítis idiopáticas. Archivos de la Sociedad Española de Oftalmología, 81: 557-562.

Coordinadora de Organizaciones de Agricultores y Ganaderos (COAG). http://www.coag.org

Echeverría, J. (2003). La revolución tecnocientífica. Madrid: FCE.

Estany, A. (2005). Progress and social impact in design sciences. En W. González (ed.), Science, Technology and Society: A Philosophical Perspective. A Coruña: Netbiblo.

Estany, A. (2006). Introducción a la filosofía de la ciencia. Cerdanyola del Vallés: Edicions Universitat Autónoma Barcelona.

Estany, A., Herrera, R. M. (2016). Innovación en el saber teórico y práctico. Londres: College Publications.

García de los Ríos, J. E., Jiménez Gómez, P. A. (2007). Hablemos de bioterrorismo. Madrid: Pearson Alhambra.

Guerrero Giampaglia, M., Vega Hernández, V. (2011). El proyecto Manhattan. Tecnología nuclear. Retrieved from: http://laplace.us.es/wiki/images/1/10/Trabajo26m.pdf

Kranzberg, M. (1967). The unity of science-technology. American Scientist, 55(1): 48-66.

Kranzberg, M. (1968). The disunity of science-technology. American Scientist, 56(1): 21-34.

Machín Osés, N. (2010). Las armas biológicas: Perspectivas de futuro. Comentario UNISCI, No 86. Retrieved from: https://www.ucm.es/data/cont/media/www/pag-72542/86MACHIN. pdf 


$$
\begin{gathered}
\text { Biología y guerra: una perspectiva pragmática } \\
\text { Anna Estany }
\end{gathered}
$$

Moya, A. C. (2017). Preparación y respuesta frente al agroterrorismo. Instituto Español de Estudios Estratégicos, No 50. Retrieved from: http://www.ieee.es/Galerias/fichero/docs opinion/2017/DIEEEO50-2017_Agroterrorismo_CiqueMoya.pdf

Niiniluoto, I. (1993). The aim and structure of applied research. Erkenntnis, 38: 1-21.

Organizaciones agrícolas y de la sociedad civil palestina (2013). Cultivando Injusticia. El comercio internacional con las compañías agrícolas israelíes y la destrucción de la agricultura palestina. Retrieved from: https://www.stopthewall.org/sites/default/files/Injusticia\%20 Agricola.pdf

Portela, R. (2016). ¿Qué es la botánica? Retrieved from: https://cienciaybiologia.com/ramas-dela-biologia-botanica/

Roll-Hansen, N. (2009). Why the distinction between basic (theoretical) and applied (practical) research is important in the politics of science. Technical Report (London School of Economics and Political Science. Centre for the Philosophy of the Natural and Social Sciences), No 4/9. London: London School of Economics and Political Science, Contingency and Dissent in Science Project.

Sánchez Ron, J. M. (1995). Ciencia, científicos y guerra en el siglo XX: algunas cuestiones éticomorales. Isegoría, 12: 119-136.

Simon, H. (1996). The science of the artificial. Cambridge, Massachusetts: The MIT Press.

Smith, J. E. (1996). Biotechnology. Cambridge: Cambridge University Press.

Sotelo, J. (2012). Las armas biológicas en tiempos de guerra. Revista Anexos, 415: 94-97.

Vengut Climent, E. (2019). Entrevista a Javier Ordóñez: Las guerras siempre empiezan con palabras. Revista online Mètode. Retrieved from: https://metode.es/noticias/entrevistas/ entrevista-a-javier-ordonez.html 